\title{
Geografia e direitos humanos: uma reflexão em tempo de pandemia Covid-19
}

\section{- Geography and human rights: a reflection in time of the pandemic Covid-19}

Alberto Pereira dos Santos ${ }^{1}$

\begin{abstract}
Resumo: Como a Geografia contribuiu, contribui e/ou pode contribuir para os avanços (e/ou para os recuos) do processo histórico de construção de uma cultura de respeito à dignidade humana? O objetivo deste sucinto artigo é responder a essa questão, como parte da proposta deste dossiê que almeja a reflexão acerca de como cada ciência, neste caso a Geografia, dialoga com os direitos humanos, no contexto deste tempo de pandemia da Covid-19. Nosso caminho ou método principal é o diálogo teórico com alguns geógrafos/as brasileiros e internacionais, que suscitam a aproximação com aspectos da temática deste escrito. As preocupações com os direitos humanos estão dispersas na Geografia, ou em obras de diversos geógrafos. O ensino de Geografia é um dos instrumentos para a democratização dos direitos humanos em todos os níveis de escolaridade, especialmente na Educação Básica.
\end{abstract}

Palavras-chave: Geografia. Direitos humanos. Ensino de Geografia, Geoética.

Abstract: How did Geography contribute, contribute and / or can contribute to the advances (and / or setbacks) of the historical process of building a culture of respect for human dignity? The purpose of this succinct article is to answer this question, as part of the proposal of this Dossier that aims to reflect on how each science, in this case Geography, dialogues with Human

1 Doutor em Geografia Humana pela FFLCH-USP. Professor do Instituto de Geografia da UERJ. E-mail: albert.geo@ uol.com.br 
Rights, in the context of this time of the Covid-19 pandemic. Our main path or method is the theoretical dialogue with some Brazilian and international geographers, who bring us closer to aspects of the theme of this writing. Concerns about Human Rights are dispersed in Geography, or in the works of several geographers. The teaching of Geography is one of the instruments for the democratization of Human Rights at all levels of education, especially in Basic Education.

Keywords: Geography. Human Rights. Teaching Geography. Geoethics.

\title{
Introdução
}

\begin{abstract}
A Geografia deve ensinar-nos, desde nossa mais tenra infância, que todos somos irmãos, seja qual for nossa nacionalidade. Em uma época como a nossa, de guerras, de sentimentos nacionalistas, e ódio habilmente alimentado por pessoas que perseguem seus próprios egoísticos interesses pessoais e de classe, a geografia deve ser - na medida em que a escola pode fazer algo para contrabalançar as influências hostis - um meio para dissipar esses preconceitos e para criar outros sentimentos mais dignos da humanidade. (KROPOTKIN, 2014, p. 38)
\end{abstract}

A epígrafe acima, do geógrafo russo Piotr Kropotkin, preconizada na Sociedade Geográfica Russa, em 1885, nos estimula a pensar sobre a seguinte questão: O que tem a ver a Geografia com os Direitos Humanos e com o processo histórico de construção de uma cultura de respeito à dignidade humana? O objetivo deste sucinto artigo é responder a essa questão, como parte integrante da proposta deste Dossiê que almeja a reflexão acerca de como cada ciência especializada dialoga com os Direitos Humanos, no contexto deste tempo de pandemia da Covid-19 neste século XXI.

Em tempo de pandemia da Covid-19, estamos assistindo a um retrocesso do papel do Brasil nas relações internacionais, como protagonista histórico e primeiro signatário da Declaração Universal dos Direitos Humanos (DUDH), promulgada em 1948 pela Organização das Nações Unidas (ONU). O Brasil - que através de seu diplomata, o médico Geraldo de Paula Souza, propôs a criação da Organização Mundial da Saúde (OMS) em 1948 e já foi um dos principais defensores deste organismo - hoje tem um governo que ataca e tenta desqualificar a OMS.

É evidente que direitos e deveres, individuais e coletivos, devem caminhar juntos. Os Direitos Humanos estão presentes nas teorias de relações internacionais, no direito internacional, nas aulas de geografia política que 
estuda a geopolítica. Nesse sentido, os Direitos Humanos são estudados pela Escola Superior de Guerra (ESG) no Estado Maior das Forças Armadas (PEREIRA DOS SANTOS, 2018).

Durante a Guerra Fria (1947 a 1991) a ONU esteve sob as influências das duas superpotências militares - EUA e URSS -, fato que dificultou seu papel na defesa e promoção dos Direitos Humanos. Lembremos que em 1991 os Estados Unidos invadiram o Iraque sem a autorização do Conselho de Segurança. Com a criação do Conselho de Direitos Humanos em 2016, a questão dos direitos humanos se fortalece nas relações internacionais neste século XXI.

O Conselho de Direitos Humanos é formado por 47 membros, eleitos para o mandato de três anos. Em 2019 o Brasil foi reeleito com 153 votos, um pouco a mais que os 137 votos da eleição de 2016. Isso, porém, não significa anuência e concordância da ONU em relação à postura e ações do atual governo brasileiro. Ao contrário, ser membro desse órgão significa estar sob os olhos e análises das Nações Unidas. A propósito, em 2018, Donald Trump, presidente dos Estados Unidos, decidiu abandonar esse Conselho, assim como também abandonou a OMS.

Minha preocupação com os Direitos Humanos existe desde o início da década de 1990, quando iniciei a carreira de geógrafo educador ou professor de geografia na periferia da zona leste da cidade de São Paulo. A Constituição Federal de 1988 era um livro inspirador utilizado para o ensino de Geografia na Educação Básica. Em 2016 e 2017 aprofundei essa experiência na pesquisa do pós-doutorado realizada na Universidade de São Paulo - USP. Surpreendente e revelador foi me deparar com o desconhecimento e/ou o senso comum por parte de alguns servidores públicos, com nível superior, no tocante aos Direitos Humanos (PEREIRA DOS SANTOS, 2018).

Como geógrafo educador há mais de trinta anos atuando no Ensino de Geografia -, desde a Educação Básica (ensino fundamental e médio, ensino magistério formação de professores e EJA - Educação de Jovens e Adultos) até o Ensino Superior e em programa de pós-graduação em Geografia - pude conviver com pessoas de todos os níveis de escolaridade, etnias, faixas etárias, condições socioeconômicas, culturais, religiosas, partidárias e de gênero. Esse convívio social e profissional favorece ao processo de auscultar as narrativas das pessoas acerca do respeito à dignidade humana ou sobre os Direitos Humanos nas múltiplas territorialidades das populações em seus diferentes territórios e lugares.

Quanto ao método para escrever este texto, optei por um breve diálogo com o pensamento de alguns geógrafos/as brasileiros e internacionais, cujas ideias e produções tangenciam a questão dos Direitos Humanos. Além disso, em razão do necessário "isolamento social" para enfrentar a pandemia da Covid-19, participei do espaço virtual ou ciberespaço através da rede social 
Facebook para auscultar um conjunto aleatório de diferentes pessoas que livremente responderam a uma única pergunta: O que você entende por respeito à dignidade humana? Em suma, as respostas convergiram para a noção acerca do respeito aos "direitos e deveres individuais e coletivos" (Art. 5, da Constituição Federal de 1988).

É um desafio enorme refletir sobre o que tem a ver a Geografia com os Direitos Humanos, afinal a gênese histórica da Geografia foi engendrada, pelo menos, a partir do século XIX. Além do tempo histórico - dialético e não linear - , existe diversidade teórica, métodos e epistemologias na ciência geográfica. Quanto à forma de apresentação, além da Introdução e Palavras finais, este artigo está organizado em duas partes complementares: a) Descobrindo os Direitos Humanos na Geografia; b) Ensino de Geografia e os Direitos Humanos na Escola. Na primeira parte a questão é: O que tem a ver a Geografia com os direitos humanos? E na segunda parte a questão é: como o ensino de geografia pode contribuir para promover a cultura de respeito à dignidade humana e aos direitos humanos? Responderemos a essas questões de modo sucinto em razão das limitações de espaço deste escrito.

\section{Descobrindo os direitos humanos na Geografia}

A Geografia é uma ciência que estuda o espaço geográfico que é a totalidade, o planeta Terra, objeto de pesquisa e estudo dos geógrafos e geógrafas (SANTOS, 1978; VESENTINI, 1986, 1992; LACOSTE, 1989). Mas os geógrafos/as que produzem as geografias são seres humanos como os outros humanos; são sujeitos históricos engajados em seus lugares e territórios com suas territorialidades carregadas de sentido, de razão e emoção, de ideias e ideologias, de crenças e descrenças, de ateísmo e religiosidades, de objetividades e subjetividades; territorialidades essas que se misturam através da intersubjetividade com outras territorialidades de outros humanos em busca permanente - a meu ver - da felicidade ou de um mundo no qual possa haver pleno respeito à dignidade humana. Essas territorialidades também são entendidas como relações interpessoais e/ou relações de poder nos territórios (RAFFESTIN, 1993; SANTOS, 1987)

Uma das lições que podemos aprender com a Geografia é aquela ensinada pelo geógrafo russo Piotr Kropotkin, proferida na Sociedade Geográfica Russa em 1885, texto em destaque como epígrafe na introdução deste escrito.

Admite-se uma "pré-história da Geografia" na Grécia Antiga com alguns pensadores como Heródoto (484-420 a. C), Hipócrates (460-370 a. C), Aristóteles (385-323 a. C). Entretanto, somente no século XIX, na Alemanha, se deu a sistematização da Geografia como ciência. (SANTOS, 1978; MORAES, 
1987). Esses pensadores antigos não eram, propriamente dizendo, "geógrafos", porém, utilizavam as ideias conceituais de espaço, paisagem, território em suas abordagens integradoras ou holísticas.

Contudo, enfatiza-se que a Geografia foi sistematizada como ciência no século XIX e, salvo exceções, fortemente influenciada pelo paradigma cartesiano, mecanicista, reducionista (CAPRA, 1994). Esse paradigma contribuiu para a formulação da visão fragmentadora de duas principais correntes teóricas na história do pensamento geográfico: Geografia Positivista e Geografia Marxista.

Sob a influência do cartesianismo - visão mecanicista, fragmentadora e reducionista - são vastamente conhecidas entre os/as geógrafos/as as ideias e argumentos acerca de duas "Escolas Geográficas": a) o determinismo geográfico ou ambiental, principalmente no pensamento do geógrafo alemão Friedrich Ratzel; b) o possibilismo geográfico, representado principalmente nas ideias do geógrafo francês Paul Vidal de La Blach (SANTOS, 1978). Entretanto, para além dessas duas visões, uma terceira visão merece ser considerada, a "Geografia libertária" representada nos escritos do geógrafo francês Élisée Reclu e do geógrafo russo Piotr Kropotkin (VESENTINI, 1986; ANDRADE, 1987).

Mas onde estariam tais contribuições da Geografia para o respeito à dignidade humana e a valorização e defesa dos Direitos Humanos? Estariam escritas ou impressas em algum período específico da história da Geografia, ou em alguma corrente de pensamento ou epistemologia geográfica? E s sas contribuições estão dispersas nas reflexões de diferentes geógrafos.

Se analisarmos o século XIX, na gênese da Geografia na Europa, podemos constatar que as principais obras do geógrafo alemão Friedrich Ratzel e do francês Paul Vidal de La Blache, em grande medida, não expressaram a preocupação com o que hoje se entende por direitos humanos. Isso porque ambos, cada um a seu modo, produziram uma "Geografia do Poder" a serviço de seus respectivos Estados-nacionais com suas ideias e conceitos que legitimaram os expansionismos e os imperialismos da Alemanha e da França (VESENTINI, 1986; LACOSTE, 1989).

Contudo, no século XIX o geógrafo francês Élisée Reclu e o geógrafo russo Piotr Kropotkin produziram obras que se identificaram com o que hoje entendemos como direitos humanos. Se considerarmos, por exemplo, o Artigo 25 da DUDH - direito ao bem-estar da pessoa e de sua família, à saúde, à alimentação, à moradia, à assistência médica - podemos dizer que esses direitos elementares estão presentes, de modo explícito ou implícito, nos escritos do geógrafo russo Piotr Kropotkin em sua obra "A conquista do pão", publicada inicialmente em 1888.

Sobre Kropotkin, o geógrafo Manuel Correia de Andrade (1987, p. 61) afirma que 
O ensino não é neutro, nem a ciência, admitindo que a Geografia [...] deveria encaminhar os estudantes para maior compreensão dos vários povos, fazendo desaparecer as fronteiras existentes, alimentar um sentimento fraterno com as diversas culturas e contribuir para a paz e a compreensão internacionais.

Por sua vez, a geógrafa Sandra Lencioni (1999), afirma que para o geógrafo russo "as ideias holísticas e a reforma social deveriam fazer parte da ciência. Para ele, não era possível se dedicar à ciência sem levar em consideração as condições sociais" (p. 112).

O geógrafo francês Yves Lacoste também tem algumas contribuições para o debate acerca dos direitos humanos, especialmente quando revela as desigualdades sociais entre países subdesenvolvidos ou países do chamado "Terceiro Mundo". Esse pensador também influenciou o pensamento geográfico brasileiro para os temas políticos e sociais (e dos direitos humanos) nas décadas de 1970 e 1980.

Embora no Brasil o pensamento geográfico tenha sido influenciado pelas "escolas geográficas" europeias, como a Geografia Tradicional positivista, da década de 1940 a 1960 - com maior domínio das obras do geógrafo Aroldo de Azevedo - podemos identificar a preocupação com temas relacionados aos Direitos Humanos nas obras do geógrafo Josué de Castro - Geografia da fome (1946) e Geopolítica da fome (1951).

Ainda no pensamento geográfico brasileiro da década de 1970 em diante, podemos identificar a preocupação com os Direitos Humanos em obras de distintos geógrafos: - Manuel Correia de Andrade, com suas obras que tratam das desigualdades regionais, dos preconceitos regionais na obra A questão do território, da exploração e colonialismo do sul/sudeste sobre o Nordeste brasileiro; - nas obras de Milton Santos, que enfatiza os direitos sociais (O espaço do cidadão, de 1987) e a exploração humana na globalização perversa e tirania do dinheiro; - nas obras de Ariovaldo Umbelino de Oliveira que tratam sobre a questão agrária, o direito à terra, os direitos dos trabalhadores rurais; - em Walter Porto Gonçalves, que trata sobre a questão ambiental e o direito ao meio ambiente; - nas obras de José William Vesentini que tratam sobre a Educação e/ou o ensino de Geografia, a formação de professores, os direitos humanos no cenário das novas geopolíticas; - em Lana Cavalcanti também sobre ensino de geografia e formação de professores; - em Raul Borges Guimarães sobre a geografia da saúde; e entre outros inúmeros geógrafos e geógrafas que tratam da geografia urbana e de outros subcampos de pesquisas e estudos geográficos (PEREIRA DOS SANTOS, 2018).

Contudo, o ensino de Geografia na Educação Básica é, a meu ver, um meio esperançoso para o processo de construção de uma cultura de respeito 
aos direitos humanos.

\section{Ensino de Geografia e os direitos humanos na escola}

Ensino de Geografia e Direitos Humanos nas Escolas é uma relação profícua, necessária e possível. Podemos dizer que é inseparável a existência de geógrafos educadores/as ou professores de geografia na escola e os Direitos Humanos, afinal, a docência requer fundamentos éticos (verdade, ação correta, paz, amor e não-violência). Quando iniciei minha carreira de professor de geografia em 1990, o Brasil havia saído do regime de ditadura de governos militares (1964-1985). O país estava saindo de um governo civil transitório - presidente Tancredo Neves e o vice José Sarney - eleito pelo Congresso Nacional em 15 de janeiro de 1985.

Ensinar geografia com a Constituição Federal de 1988 era uma das motivações na perspectiva de uma geografia humana alicerçada em valores ético-políticos. Afinal, conforme o Art. 3, os objetivos fundamentais da República Federativa do Brasil são: "I) construir uma sociedade livre, justa e solidária; II) garantir o desenvolvimento nacional; III) erradicar a pobreza e a marginalização e reduzir as desigualdades sociais e regionais". O Art. 5 estabelece os direitos e deveres individuais e coletivos. $O$ direito ao meio ambiente saudável e equilibrado e a Educação Ambiental estão no Art. 225. Enfim, nossa Constituição Federal de 1988 está em consonância e sintonia com a DUDH proclamada na Assembleia Geral da ONU em 1948.

Nos anos da década de 1980 era comum a mídia, especialmente no rádio, promover o discurso de que direitos humanos é coisa de bandido. Afinal, a pena de morte seria - na visão dos armamentistas e imediatistas - a solução do problema em relação a uma parcela dos migrantes, dos pobres, dos negros nos territórios periféricos da cidade de São Paulo. Na década de 1990, o discurso da pena de morte invadia as escolas públicas através do senso comum das crianças, adolescentes, jovens e adultos.

Nesse sentido, havia motivação pedagógica para integrar o ensino de geografia com os direitos humanos a partir da Constituição Federal do Brasil. Ou seja, havia intuitivamente a preocupação em promover a cultura de respeito à dignidade humana e sensibilizar os estudantes no tocante aos direitos humanos a partir do ensino de geografia na Educação Básica.

As possibilidades de relacionar o ensino de geografia e os direitos humanos são amplas, porém, não se deve descuidar dos conteúdos básicos nos respectivos níveis de escolaridade no Ensino Fundamental e Ensino Médio. Esse processo de ensino-aprendizagem que integra a geografia e o respeito aos direitos humanos pode ser adaptado a partir dos conteúdos e suas res- 
pectivas séries ou anos escolares. Indicaremos, de modo sucinto, os seguintes exemplos: a) populações das regiões brasileiras, b) Nordeste e preconceito regional, c) geografia das religiões/tolerância religiosa, d) populações negras/ cultura africana, e) acessibilidade das populações idosas e das pessoas com deficiência física.

Ao tratar-se do conteúdo das populações brasileiras a partir das cinco regiões geográficas - norte, nordeste, centro-oeste, sudeste e sul - pode-se, de um lado, desenvolver com os estudantes o ensino-aprendizagem do conhecimento das diversidades culturais - étnicas, linguísticas, religiosas, alimentares e outras - das respectivas populações regionais e estaduais e, por outro lado, promover a sensibilização para a cultura de respeito às diferenças no tocante ao modo de vida local, a exemplo do sertanejo (do sertão do nordeste), do caiçara (povos tradicionais do litoral paulista), dos indígenas (das regiões amazônicas), dos quilombolas (povos negros descendentes dos escravos), dos povos ribeirinhos (das florestas e margens dos rios), entre outros aspectos das culturas regionais.

Em relação ao Nordeste brasileiro, por exemplo, a geografia pode contribuir para o respeito à dignidade humana, com suas diferenças, ao ensinar que essa não é uma região homogênea; ao contrário, existem diversidades históricas, étnicas, culturais distintas entre as populações dos nove estados (Maranhão, Piauí, Ceará, Rio Grande do Norte, Paraíba, Pernambuco, Alagoas, Sergipe e Bahia) que formam a aquela região.

Em razão das intensas migrações das populações do Nordeste para a cidade de São Paulo, sobretudo nas décadas de 1970 e 1980, na capital paulista havia enorme preconceito na expressão pejorativa "baianos", bastante utilizada para se referir às populações nordestinas. Atualmente, porém, com o desenvolvimento social, a modernização e o processo de urbanização, o preconceito vem sendo diluído. Ademais, somadas às culturas dos migrantes de todos os 27 estados brasileiros, há - em São Paulo - mais de setenta nacionalidades dos imigrantes - italianos, portugueses, poloneses, japoneses, chineses, turcos, libaneses, bolivianos, venezuelanos, haitianos, nigerianos, entre outros -, nessa marcante cidade cosmopolita.

Por sua vez, na cidade do Rio de Janeiro, muitos cariocas ainda utilizam a expressão pejorativa "paraíbas" para se referirem, de modo geral, às populações migrantes do Nordeste².

Ao tratar do Nordeste brasileiro, o ensino de geografia pode também sensibilizar os estudantes a refletirem sobre as contribuições de Josué de Castro (nas-

2 Como exemplo, recentemente o atual presidente da República, numa reunião ministerial, usou a expressão "daqueles governadores de Paraíba [...]" para se referir aos governadores dos nove estados da região Nordeste. Cf. noticiado pela grande imprensa em 20 de julho de 2019. 
cido no estado de Pernambuco) e de Milton Santos (nascido no estado da Bahia). Ambos geógrafos brasileiros são internacionalmente conhecidos pelas suas análises acerca das desigualdades sociais que tanto ferem a dignidade humana.

A obra Geografia da Fome (CASTRO, 1946) analisa as carências nutricionais das populações nordestinas e de outras regiões brasileiras, demonstrando que a fome no Brasil se trata sobretudo de um problema político. Na obra Geopolítica da Fome (CASTRO, 1951) o mesmo autor demonstra que a fome é um flagelo social e político que ocorre em escala do espaço mundial - na América Latina, na África e em países do chamado Oriente Médio.

Por sua vez, as obras de Milton Santos são fundamentais para se entender as desigualdades sociais no território brasileiro. Por exemplo, O Espaço do Cidadão, de 1987, o autor analisa as desigualdades sociais nos territórios do espaço urbano, demonstrando entre outros problemas o cidadão mutilado, isto é, as fragilidades do cidadão no cotidiano que sofre as carências de serviços públicos (saúde, transporte, lazer, educação), que se configura como cidadania atrofiada, sobretudo nas periferias das cidades por ausência de políticas públicas do Estado nos três níveis de governos: municipal, estadual e federal. Desse mesmo autor, a obra Por uma outra Globalização, de 2000, contribui também para sensibilizar os estudantes acerca da tirania da informação no atual sistema ideológico, demonstrando que a violência da informação através dos meios de comunicação produz a globalização perversa que fere profundamente a dignidade humana em todas as escalas do espaço geográfico - nos níveis locais e municipais, estaduais, nacionais e internacionais.

Ainda em relação às populações negras (africanas ou afro-brasileiras) no território brasileiro, a geografia pode contribuir para promover o respeito à dignidade humana através do ensino da África e demonstrar as múltiplas fronteiras territoriais entre os Estados-nações naquele continente, bem como suas características e diferenças culturais, étnicas, linguísticas e religiosas. Pedagogicamente o ensino de geografia pode demonstrar a influência da cultura e da história das populações africanas no território brasileiro, a exemplo da culinária, da dança, da capoeira e das religiões de matrizes africanas (candomblé e umbanda) conservadas nas comunidades quilombolas.

É possível sensibilizar os estudantes para o conhecimento científico da geografia das religiões demonstrando, por exemplo, que o candomblé tem origem na cultura ioruba africana, e que chegou ao Brasil através do tráfico humano ou de pessoas - tráfico negreiro - parcelas de etnias de populações africanas foram vendidas como mercadorias e aprisionadas no sistema de trabalho escravo no Brasil, principalmente nos engenhos de cana-de-açúcar, na mineração e em outros trabalhos escravos. Por essa razão as populações africanas trouxeram suas crenças religiosas que foram sincretizadas com o ca- 
tolicismo, engendrando o que chamamos de candomblé.

É importante considerar que também é papel da educação pública sensibilizar estudantes para a tolerância religiosa como atitude ética e democrática. Nesse sentido, é válido ressaltar que, em 2008, o governo do estado de São Paulo, através da Secretaria da Educação, introduziu a Geografia das Religiões como parte do conteúdo da proposta oficial de ensino de geografia no Caderno de Geografia do $3^{\circ}$ ano do Ensino Médio. Essa proposta, que vigorou até 2018, foi fundamentada a partir de uma produção científica em Geografia Humana publicada em 2002 (PEREIRA DOS SANTOS, 2002).

Nesse sentido, o conteúdo de geografia das religiões, na perspectiva de sensibilizar estudantes para a aprendizagem e a prática da tolerância religiosa é, também, uma forma de ensino de Geografia se configurar com uma Educação em Direitos Humanos, na medida em que promove a cultura do respeito à dignidade humana, a exemplo do respeito e defesa do Art.18 da Declaração Universal dos Direitos Humanos.

Quanto ao direito humano à acessibilidade das pessoas com deficiência física, pessoas idosas e pessoas com dificuldades de mobilidade, o ensino de geografia pode contribuir para promover a cultura de respeito à dignidade humana sensibilizando e estimulando os estudantes (crianças, jovens e adultos) à observação da paisagem e do espaço público urbano reservado para essas pessoas. Segundo dados do Censo Demográfico de 2010, são mais 45 milhões de pessoas ( $23,68 \%$ do total da população) com pelo menos uma das deficiências (visual, motora, auditiva, mental) investigadas pelo Instituto Brasileiro de Geografia e Estatística (IBGE, 2010). Quanto à população idosa, com mais de 65 anos de idades, são mais de 14 milhões de pessoas ou 7,38\% do total da população.

Nesse sentido, ao sensibilizar os estudantes a observar a paisagem e o espaço público com rampas de acessibilidade (nas escolas, parques públicos, praças, hospitais, ruas e avenidas), vagas reservados em estacionamento, bem como observar os assentos reservados no transporte público para as pessoas idosas e com alguma deficiência física ou dificuldade de mobilidade, o ensino de geografia contribui para descontruir o equívoco de que os "direitos humanos é coisa de bandido" - como os preconceituosos afirmam. Desse modo, o ensino de geografia também se configura como Educação em Direitos Humanos.

\section{Palavras finais}

Os direitos humanos, enquanto construção histórica dos homens e mulheres no espaço e no tempo, merecem ser entendidos como uma meta a 
ser alcançada pela humanidade, ou melhor, como um projeto humano para o futuro da humanidade. Isso transcende, ou seja, está para além das ideologias de "esquerda" ou "direita". Trata-se de um compromisso ético-político.

Respeitar, defender e promover os direitos humanos é uma atitude ética. Ética é o "bem supremo", segundo Aristóteles, e ser ético é algo que se aprende praticando atitudes e/ou ações éticas. Nesse sentido, o processo de sensibilização e de vivências no ensino-aprendizagem acerca dos direitos humanos é uma alternativa ou caminho para a construção histórica de uma sociedade na qual o "projeto humano" seja a "Ética dos direitos humanos".

O direito ao bem-estar para todos é uma premissa da Ética dos Direitos Humanos. Nesse sentido, "A conquista do pão", do geógrafo russo Kropotkin (2014), - como ele escreveu com letras maiúsculas - continua atual neste século XXI:

\begin{abstract}
A humanidade andou bastante desde o tempo em que a pedra lascada lhe serviu para fabricar suas armas, para lutar desesperadamente pela existência. Esse período durou milhares e milhares de anos durante os quais o gênero humano acumulou tesouros incomensuráveis [...]. Hoje, o homem civilizado já ao nascer encontra um capital imenso, acumulado pelos seus antepassados. [...] O que nós proclamamos é o DIREITO AO BEM ESTAR. O BEM-ESTAR PARA TODOS. O bem-estar para todos não é um sonho. É possível, razoável, depois do que nossos maiores fizeram para tornar fecunda a nossa força de trabalho (p. 19-25).
\end{abstract}

Ainda há muito o que fazer na educação e na sociedade brasileira na defesa do respeito à dignidade humana. A questão da democracia e do Estado de Direito não é uma questão de ser ou não ser religioso, como não é uma questão de ser deísta ou ateu, o maior desafio é cada cidadão ou cidadã (inclusive os políticos profissionais) pautar suas ações cotidianas em princípios e valores éticos e sensibilizar-se para a defesa dos direitos humanos.

Tanto a religião como a ciência podem contribuir para a valorização dos direitos humanos, assim como essas duas formas de entender e compreender o mundo também colaboraram (e colaboram) para a produção de estruturas econômicas e políticas que provocaram guerras e destruição ao longo da história da civilização humana.

Como parte da democracia, partidos e igrejas têm semelhanças, ou melhor, caminham juntos, a exemplo de "parlamentares religiosos" no Congresso Nacional que atuam para seus interesses pessoais e das geopolíticas das igrejas. De modo geral, as alianças entre partidos e igrejas - a exemplo da Frente Parlamentar Evangélica, ou "bancada evangélica" - não têm interesse na educação para a autonomia das pessoas, não trabalham para a emancipação espiritual de seus seguidores (PEREIRA DOS SANTOS, 2015).

A Covid-19 não faz distinção entre as pessoas adeptas das ideologias partidárias, tampouco entre pessoas das distintas religiões e igrejas. Parece 
que os dogmatismos e os pensamentos autoritários de Lenin e Hitler ainda têm seus seguidores no Brasil e no mundo. Equem quiser que fique com essas ideologias. A liberdade de escolha, ou o livre arbítrio é um dos princípios da democracia. Nesse cenário de extremismos, acredito que o ensino de geografia na interface com os direitos humanos é um caminho alternativo para a defesa da democracia e da laicidade do Estado brasileiro.

Somente após milênios de história da humanidade - desde as civilizações do Egito, Mesopotâmia, China e outras - a ONU promulgou a Declaração Universal em 1948. Penso que a Educação em Direitos Humanos (EDH) está apenas começando neste século XXI. Vale lembrar que a proposta da EDH foi aprovada na $\mathrm{ONU}^{3}$ somente a partir da década de 1990, uma vez que as disputas militares e ideológicas entre os Estados Unidos e a antiga União Soviética, durante a Guerra Fria, dificultaram o processo educativo no tocante aos direitos humanos, como sugere George Andreopoulos ao tratar do tema Educação em direitos humanos no contexto do pós-Guerra Fria. (ANREOPOULOS, 2007).

A Educação em direitos humanos é um dos maiores desafios para nós humanos, um longo processo histórico e dialético sem data limite. A Terra é uma só, embora as fronteiras territoriais separem os Estados-nação, a humanidade é uma só. Ainda que existam as diferenças culturais - étnicas, linguísticas, religiosas, políticas -, a realidade nos desafia para a abertura aos diálogos e à aprendizagem de conviver com tolerâncias mútuas. Esse processo, porém, não exclui os conflitos interpessoais inerentes à natureza humana, à essência do homo-complexus (MORIN, 2005) que sente amor e ódio; que tem razão e intuição, riso e choro, egoísmo e altruísmo, sabedoria e loucura.

A Geografia, e seu ensino, também serve para sensibilizar as crianças, os jovens e os adultos para o exercício da cidadania nos territórios de seus municípios, defendendo o direito à saúde, o direito à moradia, o direito à alimentação, o direito à educação, o direito à religião, o direito ao lazer, o direito ao trabalho, o direito ao meio ambiente saudável, enfim o compromisso ético para com os direitos humanos. Todavia, carecemos ainda, a meu ver, de uma síntese que também perpasse Geografia, Ética e Direitos Humanos, um encontro ontológico e epistemológico em uma Geoética ${ }^{4}$.

\footnotetext{
3 Na Conferência de Viena (Áustria, junho de 1993), a Conferência Mundial dos Direitos Humanos aprovou a criação do Plano Mundial de Educação em Direitos Humanos da ONU.

4 Sobre o assunto, cf. obras de Alberto Pereira dos Santos, citadas no artigo.
} 


\section{Referências}

ANDRADE, Manuel C. Geografia, ciência da sociedade: uma introdução à análise do pensamento geográfico. São Paulo: Atlas, 1987.

ANDREOPOULOS, George J. Educação em direitos humanos no contexto pós-Guerra Fria. In: CLAUDE, Richard P. \& ANDREOPOULOS, George J. (org.). Educação em direitos humanos para o século XXI. São Paulo: EDUSP, Núcleo de Estudos sobre a Violência, 2007, p. 45-60.

CAPRA, Fritjof. O ponto de mutação. São Paulo: Cultrix, 1994.

CASTRO, Josué de. Geografia da Fome: a fome no Brasil. Rio de Janeiro: Cruzeiro, 1946.

CASTRO, Josué de. Geopolítica da Fome. Rio de Janeiro: Caso do Estudante, 1951.

IBGE - Instituto Brasileiro de Geografia e Estatística. Censo Demográfico. Rio de Janeiro, 2010.

KROPOTKIN, P. O que a geografia deve ser? In: KROPOTKIN, P.; RÉCLUS, É. Escritos sobre educação e geografia. São Paulo: Terra Livre, 2014.

KROPOTKIN, P. A conquista do pão. Rio de Janeiro: Achiamé, 2014.

LACOSTE, Yves. A Geografia - isso serve, em primeiro lugar, para fazer a guerra. Campinas-SP: Papirus, 1989.

LENCIONI, Sandra. Região e Geografia. São Paulo: Edusp, 1999.

MORAES, Antonio C. R. Geografia - pequena história crítica. 7. ed. São Paulo: Hucitec, 1987.

MORIN, Edgar. Os sete saberes necessários à educação do futuro. 10. ed. São Paulo: Cortez/Unesco, 2005.

PEREIRA DOS SANTOS, Alberto. Geografia e educação em direitos humanos na cidade de São Paulo. GeoUERJ, Rio de Janeiro, n. 33, p. 1-22, 2018. 
PEREIRA DOS SANTOS, Alberto. Geopolítica das igrejas e anarquia religiosa no Brasil: por uma Geoética. Rio de Janeiro: Faperj/Gramma, 2015.

PEREIRA DOS SANTOS, Alberto. Geoética e relações internacionais. GeoUERJ, Rio de Janeiro, n. 24, p. 479-508, 2012.

PEREIRA DOS SANTOS, Alberto. Introdução à Geografia das religiões. GEOUSP, São Paulo, n. 11, p. 22-33, 2002.

RAFFESTIN, Claude. Por uma geografia do poder. São Paulo: Ática, 1993.

SANTOS, Milton. Por uma geografia nova. São Paulo: Hucitec, 1978.

SANTOS, Milton. O espaço do cidadão. São Paulo: Hucitec, 1987.

SANTOS, Milton. Por uma outra globalização: do pensamento único à consciência universal. Rio de Janeiro: Record, 2000.

VESENTINI, J. William. A capital da geopolítica. São Paulo: Ática, 1986.

VESENTINI, J. William. Para uma geografia crítica na escola

* Agradeço a todas as pessoas que participaram virtualmente da pesquisa respondendo o que entendem por respeito à dignidade humana: Adão, Adão Barbosa, Afonso, Alexandre, Alessandra, Amália, Angélica, Ângela, Aroldo, Ana Maria, Carla, Cleber, Damião, Dulce, Eliane, Eliene, Eliete, Gislene, Homero, José Carlos, Joceli, Letícia, Luciana, Marcia, Marta, Rogério, Sabrina, Valéria e Vittória. 